\title{
Awareness and knowledge of glaucoma and associated factors among adults: a cross sectional study in Gondar Town, Northwest Ethiopia
}

Destaye Shiferaw Alemu*, Alemayehu Desalegn Gudeta and Kbrom Legesse Gebreselassie

\begin{abstract}
Background: Raising public awareness and knowledge about glaucoma is a key for early case identification and prevention of blindness. However, awareness and knowledge about glaucoma is unknown at community level, making provision of interventions difficult. This study was intended to assess the awareness and knowledge of adults about glaucoma and the factors affecting it in Gondar town, Northwest Ethiopia.

Methods: Community based cross - sectional study was conducted on 701 adults 35 and above years in Gondar from April 12-30, 2016. Multistage sampling technique was used to select study participants. Interviewer administered pretested structured questionnaire was used to collect data after verbal informed consent. Data were entered into EpiData version 3.1 and analyzed by Statistical Package for Social Sciences version 20. Bivariate and multivariate logistic regression models and Odds ratio with 95\% interval were used to identify factors. P-value $<0.05$ was considered statistically significant.
\end{abstract}

Results: Seven hundred one adults age 35 and above years were participated with a response rate of $99.3 \%$. The male to female ratio was 1:1.6 with median age of 48 years with interqurtile range of 20 . The proportion of awareness was $35.1 \%$ (95\% Cl: 31.5\%, 38.6\%). Good knowledge was demonstrated in 49.6\% (95\%Cl: 43.3\%, 55\%) of glaucoma aware participants. Education (primary [AOR: 3.21; 1.73, 5.95], secondary [AOR: 4.34; 2.30, 8.22]; college and above [AOR: 9.82; 4.27, 22.60]) and having eye examination [AOR: $2.78 ; 1.86,4.15]$ were positively associated with awareness of glaucoma whereas older age (65 -74 years [AOR: $0.31(0.21,0.76])$ was inversely related. Level of Education (primary[AOR:2.83;1.04,7.71],secondary[AOR:3. 45;1.33,9.41],college and above [AOR: 4.86;1.82,12,99] and having eye examination [AOR: 2.61;1.53,4.45] were significantly associated with knowledge.

Conclusion: The study has indicated higher level of awareness and knowledge about glaucoma in urban communities than previous studies. It has also identified educational status, eye examination at least once in life are related with better awareness and knowledge. The present awareness and knowledge should be enhanced through public oriented glaucoma education via mass media and incorporating eye check up as a routine in older people.

Keywords: Awareness, Glaucoma, Knowledge, Gondar, Ethiopia

\footnotetext{
* Correspondence: destayest@gmail.com

Department of Optometry, College of Medicine and Health Sciences,

University of Gondar, P.O. BOX: 196 Gondar, Ethiopia
} 


\section{Background}

Glaucoma is a group of eye diseases with characteristic features of optic disc and specific pattern of visual field defects [1]. The process of optic nerve damage is usually progressive and asymptomatic [2]. Intraocular pressure is the only modifiable risk factor [3] and other several risk factors have been identified [4-8].

Primary open-angle glaucoma (POAG) is the most common type of glaucoma in whites and Afro-Caribbean accounting $2 \%$ of visual impairment and $8 \%$ of blindness [9].

Glaucoma is a non - communicable, chronic eye disease which needs the principles of long-term care [10].

The asymptomatic nature along with the irreversible blindness it causes makes glaucoma a public health challenge [11] and the second cause of avoidable blindness globally [12].

Approximately, 15\% of global blindness is due to glaucoma and around 600,000 people go blind annually [13]. In 2010, 60.5 million people were victims of glaucoma globally [14]. This is expected to rise to 76 million in 2020 and 111 million in 2040 [15].It was also reported that 57.5 million people were affected in 2015 by POAG alone [16].

Blindness due to glaucoma is highest in Africa [14] accounting 15\% [17] of the global blindness (4.20\%) [18]. The situation is worse in Sub Saharan Africa [17] where poor awareness and knowledge further compounded the condition. In Ethiopia, glaucoma is the fifth cause of blindness causing an irreversible sight loss for an estimated of 62,000 Ethiopians [19].

Glaucoma blindness imposes significant economic burden not only for individuals affected [20] but also it increases healthcare cost [21], impairs quality of life, increases rehabilitation cost for the blind which all affects the economic growth of a nation [22]. It also results a huge burden for the healthcare system and government's spending toward health care [23].

Early detection and timely treatment are important to avert the consequences from such silent thief of sight [24]. As most cases occur among the productive age group, preventing early blindness from glaucoma is basically not only a matter of saving individuals sight loss but also saving nations economy [25].

Public awareness and knowledge of glaucoma plays a significant role in raising public health seeking behavior for regular eye check and increases the chance of identifying undetected cases [26]. It is also clinically beneficial and cost effective to delay visual field deterioration [27, 28] and improve treatment compliance [12, 29, 30]. Contrary to this, failure to aware leads to late detection and poses management problem in preventing blindness from glaucoma [13]. Despite this fact, poor public awareness and knowledge about glaucoma is the major gap. In the developed world, less than $50 \%$ of people with glaucoma are aware of it [31], almost $70 \%$ of cases are not detected [32] and 39\% of them present with advanced stage of the disease in at least one eye [33]. This is worse in developing countries where few people are aware and knowledgeable about glaucoma [34, 35].

Raising public awareness and knowledge of glaucoma is a key means of addressing the overwhelming consequences of the disease [2, 36, 37].Cognizant to this, international directives [38] including the World Health Organization's Vision 2020 campaign [12] took glaucoma one of its main priority area.

It would appear that the global Vision 2020 initiative has placed glaucoma as a seventh eye disease priority [39]. The World Glaucoma Association (WGA) and the World Glaucoma Patient Association (WGPA) extended 'World Glaucoma Day' to 'World Glaucoma Week (WGW)' to help people understand the distressing effects of the disease [14]. In Africa, the WGA 1st Africa glaucoma summit in Ghana in 2010 [40] and the Kampala, Uganda, resolution in 2012 [41] were some to mention some.

In Ethiopia, efforts have been done to raise public awareness of glaucoma. In 2007, a group of volunteers consisting of physicians and glaucoma patients set up the Glaucoma Group aimed at increasing public awareness of glaucoma supported by the ophthalmological Society of Ethiopia (OSE) and the ministry of health every year, during World Glaucoma Week [24]. However, evidence on public awareness and knowledge about glaucoma is limited in Ethiopia except a few institution-based studies in some parts of the country. These pocket studies may not reflect the real picture of awareness and knowledge in the public about glaucoma as they were few and mainly institution based. Hence, this study was aimed to investigate the awareness and knowledge of adults towards glaucoma and associated factors in Gondar town, Ethiopia.

There is a widely accepted notion that awareness leads to knowledge and knowledge to behavior [42]. However, published evidences indicates that awareness and knowledge about glaucoma is limited across the globe [40-61].

Various factors influence awareness and knowledge about glaucoma. In the available literatures level of education $[13,40,41,44,46,49,51,61-63]$, family history of glaucoma [46, 63], age [40], economic status ([13, 40, $48,51])$, sex [44, 48], type of occupation [51, 64], having chronic disease like diabetes and hypertension [20] and having eye examination [64] were associated with awareness and knowledge of glaucoma.

Public awareness and knowledge plays a paramount role for early detection and timely treatment of glaucoma. This delays early blindness from glaucoma. It is also equally important to design most effective awareness raising strategies based on identified factors affecting the awareness and knowledge about glaucoma. 
There is, however, as far as our web site database search was concerned, paucity on awareness and knowledge about glaucoma and the associated factors in Ethiopia in general and the study area in particular. The present study intended to fill this gap while serving as a baseline for further studies to generate inputs for eye health care providers and policy makers to design evidence based interventions to lessen the alarmingly increasing blindness from glaucoma.

\section{Methods}

\section{Study design and study area}

A community based cross- sectional was study carried out in Gondar town, Northwest Ethiopia. Gondar has an estimated population of 210,000 ( $47.4 \%$ males, $52.6 \%$ females) [65] and is one of the largest towns of the country. The town has 21 kebeles (smallest administrative units in Ethiopia) with 53,725 households [65]. There is a referral University hospital with a tertiary eye care center. The eye care center provides general and various specialty ophthalmic services, including glaucoma. There are also few private ophthalmic clinics in the town, which provide general eye care services. The study period was from April 12-30, 2016.

\section{Source and study population}

The source population for the study was all adults (age 35 and above years) in Gondar town (This segment of the population was targeted for the study to reflect the awareness and knowledge of glaucoma among the population most at risk).

\section{Inclusion and exclusion criteria}

All permanent residents (lived at least 6 months) in the study area whose age was 35 and above years were eligible to participate in the study while permanent residents age 35 and above years who were eye care professionals and individuals who were seriously ill to answer the study questions were excluded.

\section{Variables of the study}

The outcome variables were awareness and knowledge of glaucoma while the independent variables include socio - demographic factors: age, sex, religion, marital status; socio-economic factors: educational level, type of occupation, income; health related factors: history of diabetes, history of hypertension, family history of glaucoma, history of eye examination.

\section{Operational definitions}

\section{Aware}

A participant was classified as aware of glaucoma if a positive response ('Yes') was obtained to the question 'have you ever heard of glaucoma?' and gave at least one answer such answers as 'glaucoma is high eye pressure', 'glaucoma is high eye pressure causing blindness', 'glaucoma causes damage to the eye nerve', blinding eye disease causing eye nerve damage, eye disease cause visual field loss [60]. In this study, hearing glaucoma alone was not considered as awareness because merely being aware of the term did not ensure awareness about the disease. In a previous study, on a similar topic in Ethiopia [60] and the pretest procedure of this study indicated that participants who said "Yes" for the question "have you ever heard of glaucoma?' were meant to them 'trachoma'. Probably trachoma is common in the study area and the two conditions, "Trachoma" and "Glaucoma" have similar suffix ('-oma') as well as there is no common Amharic (local language term) equivalent for glaucoma.

\section{Knowledge}

Respondents who scored the mean $(\geq 8.42)$ and above of the knowledge questions were considered to have good knowledge while those who score below the mean were considered as having poor knowledge.

\section{Scoring}

Fifteen questions adapted from previous studies [44, 60], were used to assess respondents' knowledge about glaucoma. One point was allocated for each correct response; otherwise, zero was given.

\section{Sample size determination}

Sample size was determined separately for awareness, knowledge and factors to address the objectives. The single population proportion formula was considered to address the first two objectives with the assumption of $95 \%$ confidence level $\left(\mathrm{Z}_{\mathrm{a} / 2}=1.96\right), 5 \%$ maximum allowable error (w), 10\% non-response and a design effect 2 for multistage sampling. Accordingly, the sample size required for awareness (considering proportion of awareness $p=0.284$ ( [61]) was 689. The calculated sample size for knowledge based on the proportions of, $p=0.703$ for good knowledge [61] was 706. The power approach, using StatCalc (Epi info 7), was used to calculate sample size to address the objectives for factors based on variables which were statistically significant in previous studies (educational level, age, sex) [61]. Educational status was the most repeatedly statistically significant variable and sample size was determined considering a power of $80 \%$, non- exposed to exposed ratio 1:1, confidence level of $95 \%$, design effect of 2 for multistage sampling and 10\% for nonresponse. The sample size based on this factor was 185 and for the other two was 156 (for age) and 110 (for sex). The final sample size required for the study was 706 adults (Additional file 1). 


\section{Sampling technique}

Multistage sampling technique was used for the sampling process. Initially, $20 \%$ of the total "kebeles" were selected using simple random sampling technique after obtaining their list from the local administration office. The required sample from each kebele was allocated according to the proportion to size of each kebele population. The sampling fraction $(\mathrm{k}=22)$ was determined by taking the ratio of households in the respective selected kebele to the sample size selected in each kebele. (i.e. $\mathrm{k}=\mathrm{Ni} / \mathrm{ni}$, where $\mathrm{Ni}=$ total population in each selected kebele and $\mathrm{ni}=$ sample size taken from each selected kebele). Then, households were selected using systematic random sampling technique. Finally, one eligible adult was selected from each household using simple random sampling. The next immediate household was taken when no person selected fulfilled the eligibility criteria of the study (Additional file 2).

\section{Data collection tool}

The questionnaire was adapted from previous studies $[44,60]$. It was initially prepared in English by the principal investigator, translated into Amharic (local language) by language expertise, and re-translated to English to check consistency in meaning of words and concepts. Most questions were closed ended. The questionnaire consisted of background information and questions to measure awareness and knowledge of glaucoma (Additional file 3). It was pretested and modified prior to actual data collection.

\section{Data collection procedures}

Before starting data collection, from which direction to start was determined by tossing a coin being at a prominent landmark (road, big buildings). The first household was the first number between one and the sampling fraction $(k=22)$.

Then data collectors (five BSc optometrists) contacted the house head and the study participant and obtained permission to proceed interviewing using Amharic version of the questionnaire. Study participants who responded for the awareness questions were further asked the knowledge questions. Weekends were preferred to other days for data collection to maximize the chance of getting study participants (Additional file 4).

\section{Data quality assurance}

To assure quality, one-day training was given to data collectors and supervisors by the principal investigator on how to use the questionnaire and the data collection procedure as well as the sampling technique. The questionnaire was pretested prior to the actual data collection on 5\% of the sample [35] who fulfilled the sampling inclusion criteria in an area with similar characteristic outside the study area (Teda town). Modifications were made accordingly. The supervisor and principal investigator supervised data collection process. The completeness, accuracy and clarity of data were checked on daily bases. EpiData version 3.1 was used for data entry after coding.

\section{Data management and analysis}

Data were entered into EpiData version 3.1 and exported to Statistical Package for Social Science (SPSS) version 20 for analysis. Data were cleaned using frequencies and cross tabulations. Data were described using summary measures (frequencies, proportions means). Proportions were estimated along with 95\% CI. Both bivariate and multivariate logistic regression analyses were carried out. Variables with $p$ value $<0.2$ in the bivariate analysis were fitted into the multivariate logistic regression model for prediction of determinants. Enter method was used for variable selection. The Hosmer-Lemeshow goodness-offit statistic (0.76) was used to assess whether the necessary assumptions for the application of multiple logistic regression were fulfilled. Crude and adjusted odds ratio with $95 \%$ confidence interval were computed. The Adjusted Odds ratio with $95 \%$ confidence interval was used to measure the strength of association and the actual predictors of the outcome variables. $P$-values less than 0.05 were considered statistically significant.

\section{Results}

Socio - Demographic characteristics of study population A total of 706 adults age 35 and above years were initially planned to participate in the study, however; five participants refused to participate, and were excluded from the study giving a response rate of $99.3 \%$. The sex proportion of the participants was almost equal with male to female ratio of $1: 1.6$. The median ( \pm IQR) age was $48( \pm 20)$ years.

Majority of the respondents were Orthodox Christian in religion (77.6\%) and Amhara in ethnicity (84.9\%). More than two-third (68.3\%) were married and less than one - third (30.1\%) were housewives. About two out of five participants (42\%) were in the age group $35-44$ years and almost one - third had no formal education (32.7\%) (Table 1).

\section{Medical and glaucoma related characteristics in the study population}

Ninety-three (13.3\%) study participants had self-reported history of established hypertension, yet 35(37.6\%) of them never examined their eyes. Among 58(8.3\%) respondents with diabetes mellitus, 22 (37.9\%) of them had never eye checkup in their life. Among respondents with family history of glaucoma [21], 38.1\% [8] had never eye examination. Two hundred sixty - one (37.2\%) of the respondents had history of eye examination at least once in their lifetime. 
Table 1 Socio-demographic characteristics of study population, Gondar town, Northwest Ethiopia, April 2016 ( $n=701)$

\begin{tabular}{lll}
\hline Characteristics & Frequency & Percent \\
\hline Sex & & \\
Female & 376 & 53.6 \\
Male & 325 & 46.4
\end{tabular}

Age (years)

$\begin{array}{lll}35-44 & 296 & 42.1 \\ 45-54 & 163 & 23.3 \\ 55-64 & 112 & 16.0 \\ 65-74 & 74 & 10.6 \\ \geq 75 & 56 & 8.0\end{array}$

Religion

Orthodox

Muslim

Others*

Ethnicity

Amhara

Tigrie

Kmant

Others**

Level of education

No formal education

Primary education

Secondary education

College and above

Marital status

Single

Married

Divorced

Widowed

Type of occupation

Merchant

Housewife

Government employed

Self-employed

No job

Farmer

Daily laborer

Others ${ }^{* * *}$

Monthly income in ETB $(n=617)$

$\begin{array}{lll}\leq 750 & 174 & 28.2 \\ 751-1300 & 116 & 18.8 \\ 1301-2000 & 130 & 21.1 \\ >2000 & 197 & 31.9\end{array}$

Others*protestant, Jewish; Others**Oromo, Guragie; Others***retired, driver, waiver, religious leaders, ETB: Ethiopian birr
Among these, about three fourth had at least one examination in the last 12 months and one fourth of them had before 12 months (Table 2).

Table 2: Medical and glaucoma related characteristics of study population, Gondar town, Northwest Ethiopia, April 2016.

\section{Awareness of adults towards glaucoma}

Three hundred forty (48.5\%) respondents had heard of glaucoma. Nevertheless, it was only 246 (35.1\% [95\% CI: $31.5 \%, 38.6 \%]$ ) of them were aware of glaucoma. The mean age for respondents who were aware of glaucoma was $51.73(\mathrm{SD} \pm 14.34$ ) and for those who were not aware was $47.95( \pm 11.74)(p<0.001)$. Higher proportions $(43.52 \%)$ of adults without formal education were not aware of glaucoma (Fig. 1).

Table 2 Medical and glaucoma related characteristics of study population, Gondar town, Northwest Ethiopia, April 2016

\begin{tabular}{|c|c|c|}
\hline Characteristics & Frequency & Percent \\
\hline \multicolumn{3}{|l|}{ History of hypertension $(n=701)$} \\
\hline Yes & 93 & 13.3 \\
\hline No & 551 & 78.6 \\
\hline Do not know (not screened) & 57 & 8.1 \\
\hline \multicolumn{3}{|l|}{ History of diabetes $(n=701)$} \\
\hline Yes & 58 & 8.3 \\
\hline No & 582 & 83.0 \\
\hline Do not know & 61 & 8.7 \\
\hline \multicolumn{3}{|c|}{ History of eye examination ( $n=701)$} \\
\hline Yes & 261 & 37.2 \\
\hline No & 440 & 62.8 \\
\hline \multicolumn{3}{|l|}{ Eye examination $(n=261)$} \\
\hline Within 12 months & 194 & 74.3 \\
\hline Before 12 months & 67 & 25.7 \\
\hline \multicolumn{3}{|l|}{ History of glaucoma ( $n=261$ ) } \\
\hline Yes & 18 & 6.9 \\
\hline No & 223 & 85.4 \\
\hline Do not know & 20 & 7.7 \\
\hline \multicolumn{3}{|c|}{ Family history of glaucoma $(n=246)$} \\
\hline Yes & 21 & 8.5 \\
\hline No & 177 & 72.0 \\
\hline Do not know & 48 & 19.5 \\
\hline \multicolumn{3}{|c|}{ Family member with glaucoma $(n=21)$} \\
\hline Mother & 9 & 42.9 \\
\hline Brother & 5 & 23.8 \\
\hline Father & 4 & 19.0 \\
\hline Sister & 2 & 9.5 \\
\hline Father and brother & 1 & 4.8 \\
\hline
\end{tabular}




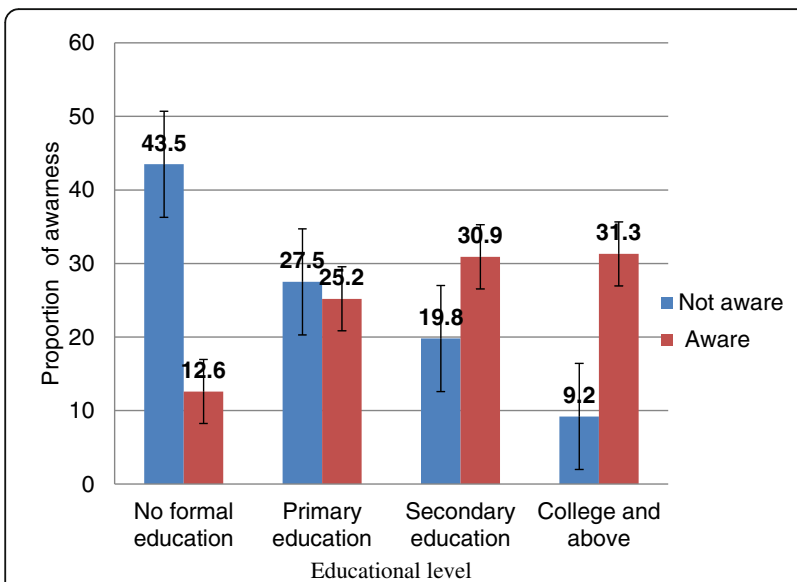

Fig. 1 Proportion of awareness of glaucoma across educational level of respondents with $95 \% \mathrm{Cl}$ error bar among adults age 35 and above years, Gondar town, Northwest Ethiopia, 2016 $(n=701)$

\section{Source of information about glaucoma}

The respondents had multiple sources of information about glaucoma. Mass media (television and radio) followed by health care providers and people with glaucoma were the main sources of information (Fig. 2).

\section{Knowledge of glaucoma among respondents who were aware of glaucoma}

Among 246 study participants who were aware of glaucoma, 122 (49.6\% [95\% CI: 43.33\% - 56.9\%]) had good knowledge about glaucoma while 124(50.4\%) had poor

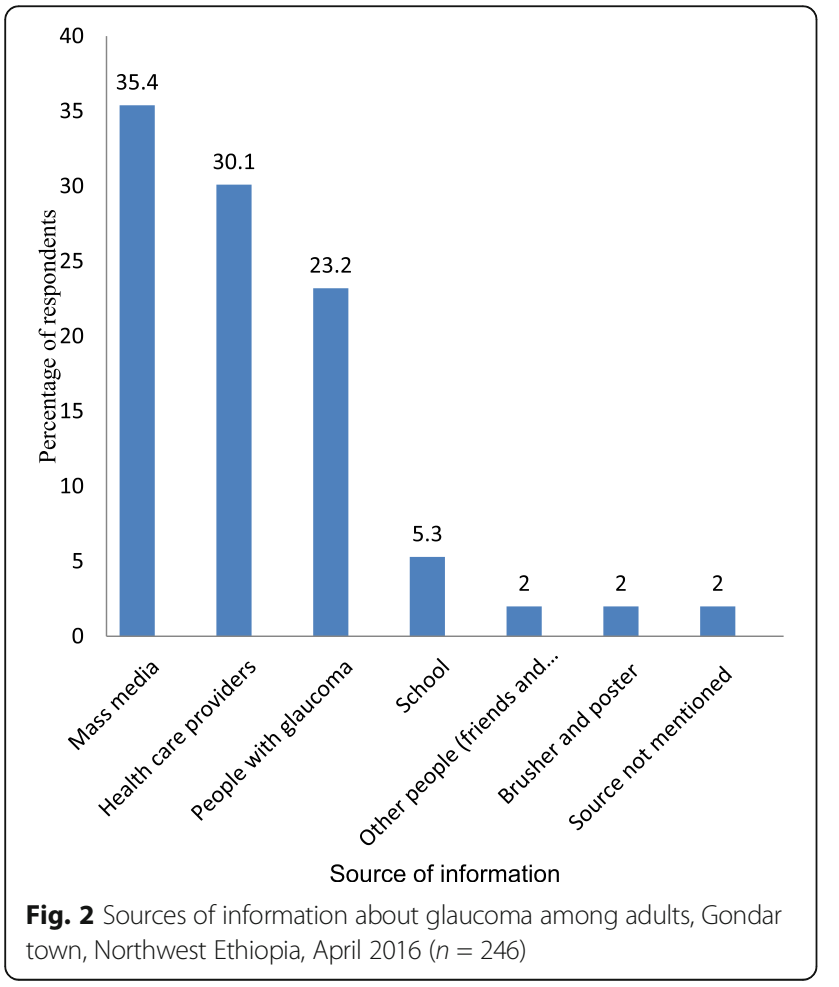

knowledge. The mean knowledge score of glaucoma was $8.42( \pm 2.7 \mathrm{SD})$ with a maximum possible score of 15. Seventy-three (29.7\%) males, 89(36.2\%) married, 22(8.9\%) hypertensives, 15(6.1\%) diabetics, 77(31.3\%) with eye examination and $6(4.8 \%)$ respondents with glaucoma and $9(3.7 \%)$ with family history of glaucoma had good knowledge (Table 3).

\section{Factors associated with awareness of glaucoma}

In this study age, sex, marital status, educational level, type of occupation, history of hypertension, history of diabetes mellitus and having had eye examination were associated with awareness of glaucoma at 0.2 level of significant in the binary logistic regression analysis.

However, after adjusting for potential confounders in the multivariate analysis, educational level (primary education [AOR: 3.21; 1.73, 5.95], secondary education [AOR: 4.34; 2.30, 8.22], college and above [AOR: 9.82; 4.27, 22, 60]) and having had eye examination at least once in life (AOR: $2.78 ; 1.86,4.15$ ) were directly associated with awareness of glaucoma. Nevertheless, age (group $65-74$ [AOR: $0.31 ; 0.21,0.76]$ ) was inversely associated.

Accordingly, adults with primary education were 3.2 times more likely to be aware of glaucoma compared with adults with no formal education. Similarly, adults with secondary education were 4.34 times more aware of glaucoma compared with adults with no formal education. Furthermore, adults with college and above education were nearly ten times more likely to be aware of glaucoma than adults without formal education. Adults with at least one eye examination in their life were nearly three times more likely to be aware of glaucoma than adults who had never examined their eyes.

People whose ages between 65 and 74 years were $69 \%$ less aware of glaucoma compared with their counterparts in the age range 35-44 years. Awareness of glaucoma was independent of, sex, marital status, type of occupation, history of hypertension and history of diabetes mellitus (Table 4).

\section{Factors associated with knowledge of glaucoma}

Sex, educational status and history of eye examination were significantly associated with good knowledge in the bivariate logistic regression analysis. Educational status and having eye examination at least once in life are independent predictors of good knowledge after controlling potential confounders.

Accordingly, adults with primary education were nearly three times (AOR: $2.83 ; 1.04,7.71$ ) more likely to have good knowledge than adults without formal education. Similarly, the likelihood of having good knowledge among adults with secondary education was more than three times (AOR: 3.53; 1.33, 9.41) higher than adults without formal education. Furthermore, the likelihood of having 
Table 3 Knowledge of glaucoma across socio- demographic characteristics of respondents, Gondar town, Northwest Ethiopia, April $2016(n=246)$

\begin{tabular}{|c|c|c|}
\hline \multirow[t]{2}{*}{ Characteristics } & \multicolumn{2}{|c|}{ Knowledge status } \\
\hline & Good N (\%) & Poor N (\%) \\
\hline \multicolumn{3}{|l|}{ Sex } \\
\hline Male & 73(29.7) & $64(26.0)$ \\
\hline Female & 49(19.9) & $60(24.4)$ \\
\hline \multicolumn{3}{|l|}{ Age (years) } \\
\hline $35-44$ & $50(20.3)$ & $62(25.2)$ \\
\hline $45-54$ & $38(15.4)$ & $31(12.6)$ \\
\hline $55-64$ & $24(9.8)$ & $18(7.3)$ \\
\hline $65-74$ & $6(2.4)$ & $4(1.6)$ \\
\hline$\geq 75$ & $4(1.6)$ & $9(3.8)$ \\
\hline \multicolumn{3}{|l|}{ Level of education } \\
\hline No formal education & $7(2.8)$. & $24(9.8)$ \\
\hline Primary education & 28(11.3) & $34(13.8)$ \\
\hline Secondary education & $41(16.7)$ & $35(14.3)$ \\
\hline College and above & $46(18.7)$ & $31(12.6)$ \\
\hline \multicolumn{3}{|l|}{ Religion } \\
\hline Orthodox & $94(38.2)$ & $94(38.2)$ \\
\hline Muslim & $25(10.2)$ & $27(11.0)$ \\
\hline Others* & $3(1.2)$ & $3(1.2)$ \\
\hline \multicolumn{3}{|l|}{ Ethnicity } \\
\hline Amhara & $99(40.2)$ & $105(42.7)$ \\
\hline Tigrie & $9(3.7)$ & $10(4.1)$ \\
\hline Kmant & $13(5.3)$ & $6(2.4)$ \\
\hline Others** & $1(0.4)$ & $3(1.2)$ \\
\hline \multicolumn{3}{|l|}{ Marital status } \\
\hline Single & $12(4.9)$ & $6(2.4)$ \\
\hline Married & $89(36.2)$ & $97(39.4)$ \\
\hline Divorced & $12(4.9)$ & $10(4.0)$ \\
\hline Widowed & $9(3.7)$ & $11(4.5)$ \\
\hline \multicolumn{3}{|l|}{ History of hypertension } \\
\hline Yes & $22(8.9)$ & $22(8.9)$ \\
\hline No & 98(39.8) & $93(37.8)$ \\
\hline Do not know (unscreened) & $2(0.8)$ & $9(3.8)$ \\
\hline \multicolumn{3}{|l|}{ History of diabetes mellitus } \\
\hline Yes & $15(6.1)$ & $12(4.9)$ \\
\hline No & 104(42.3) & 106(43.1) \\
\hline Do not know (unscreened) & $3(1.2)$ & $6(2.4)$ \\
\hline \multicolumn{3}{|l|}{ History of eye examination } \\
\hline Yes & 77(31.3) & 49(19.9) \\
\hline No & $45(18.3)$ & $75(30.5)$ \\
\hline \multicolumn{3}{|l|}{ History of glaucoma*** } \\
\hline Yes & $6(4.8)$ & $7(5.6)$ \\
\hline No & $69(54.8)$ & $38(30.2)$ \\
\hline
\end{tabular}

Table 3 Knowledge of glaucoma across socio- demographic characteristics of respondents, Gondar town, Northwest Ethiopia, April $2016(n=246)$ (Continued)

\begin{tabular}{lll}
\hline Do not know & $2(1.6)$ & $4(3.2)$ \\
Family history of glaucoma & & \\
Yes & $9(3.7)$ & $5(2.0)$ \\
No & $106(43.2)$ & $78(31.6)$ \\
Do not know & $34(13.8)$ & $14(5.7)$ \\
\hline Others* $=$ Protestant \& Jewish, Others** & Oromo \&Guragie
\end{tabular}

good knowledge among adults with college and above education was almost five times (AOR: 4.86; 1.82, 12.99) higher than those adults without formal education. The likelihood of good knowledge about glaucoma among adults who had at least one eye examination in their life was 2.6 times higher (AOR: $2.61 ; 1.53,4.45$ ) compared to adults who had never an eye examination in their life (Table 5).

\section{Discussion}

This population based cross sectional study determined the awareness and knowledge level of adults about glaucoma and the associated factors in Gondar town, Northwest Ethiopia.

In the present study, the proportion of awareness was $35.1 \%$ (95\% CI: 31.5\%, 38.6\%) while good knowledge among respondents who were aware of glaucoma was 49.6\% (95\%CI: 43.3, 55). Educational status (having at least formal education), eye examination at least once in life were directly related to better awareness about glaucoma whereas older age was inversely related. Similarly, higher level of education and having eye examination at least once in life were determinants of good knowledge about glaucoma.

The proportion of awareness about glaucoma (35.1\%) in the present study is higher than a finding from previous study in Ethiopia [61]. This is expected from such an urban-based population study where people have access to health related information at least due to geographic proximity to information [66].

The current level of glaucoma awareness (35.1\%) is better as compared to reports from Agaro town in Jimma (2.4\%), Southwest Ethiopia, in 2009 [60]. This may reflect the variation in demographic characteristics of the study population between the two studies. In the Agaro study, about $43 \%$ participants were not able to read and write while in the current study only $32.7 \%$ participants had no formal education. Additionally, participants in the former study were primarily rural residents coming for outreach service. This could be source of the discrepancy as people living in remote rural areas might have less chance of getting health related information [50]. Age difference among study participant might 
Table 4 Bivariate and multivariate logistic regression of factors associated with awareness of glaucoma among adults age 35 and above years, Gondar town, Northwest Ethiopia, April $2016(n=701)$

\begin{tabular}{|c|c|c|c|c|}
\hline \multirow[t]{2}{*}{ Variables } & \multicolumn{2}{|c|}{ Awareness } & \multirow[b]{2}{*}{ COR $(95 \% \mathrm{Cl})$} & \multirow[b]{2}{*}{ AOR $(95 \% \mathrm{Cl})$} \\
\hline & Aware & Not aware & & \\
\hline \multicolumn{5}{|l|}{ Age category (years) } \\
\hline $35-44$ & 112 & 184 & 1.00 & 1.00 \\
\hline $45-54$ & 89 & 74 & $1.21(0.82,1.78)$ & $1.27(0.78,2.10)$ \\
\hline $55-64$ & 54 & 58 & $0.99(0.63,1.54)$ & $1.29(0.72,2.32)$ \\
\hline $65-74$ & 27 & 47 & $0.26(0.13,0.52)^{* * *}$ & $0.31(0.21,0.76)^{*}$ \\
\hline$\geq 75$ & 17 & 39 & $0.50(0.26,0.96)^{*}$ & $0.81(0.32,2.05)$ \\
\hline \multicolumn{5}{|l|}{ Sex } \\
\hline Male & 137 & 188 & 1.00 & 1.00 \\
\hline Female & 109 & 267 & $0.56(0.41-0.77)^{* * *}$ & $0.74(0.46,1.20)$ \\
\hline \multicolumn{5}{|l|}{ Level of education } \\
\hline No formal education & 31 & 198 & 1.00 & 1.00 \\
\hline Primary education & 62 & 125 & $3.17(1.95,5.15)^{* * *}$ & $3.21(1.73,5.95)^{*}$ \\
\hline Secondary education & 76 & 60 & $5.39(3.32,8.77)^{* * *}$ & $4.34(2.30,8.22)^{* *}$ \\
\hline College and above & 77 & 42 & $11.71(6.87,19.9)^{* * *}$ & $9.82(4.27,22.60)^{* * *}$ \\
\hline \multicolumn{5}{|l|}{ Marital status } \\
\hline Single & 18 & 35 & $1.23(0.68-2.24)^{* *}$ & $0.93(0.45,1.92)$ \\
\hline Married & 186 & 293 & $1.16(0.53-2.51)^{*}$ & $1.30(0.49,3.43)$ \\
\hline Divorced & 22 & 37 & $0.43(0.21-0.91)^{* * *}$ & $1.04(0.39,2.81)$ \\
\hline Widowed & 20 & 90 & 1.00 & 1.00 \\
\hline \multicolumn{5}{|l|}{ Type of occupation } \\
\hline Merchant & 90 & 126 & 1.00 & 1.00 \\
\hline Housewife & 45 & 166 & $0.38(0.25-0.58)^{* * *}$ & $0.92(0.51,1.67)$ \\
\hline Government employed & 66 & 49 & $1.89(1.19-2.98)^{* *}$ & $0.92(0.48,1.74)$ \\
\hline Others & 33 & 7143 & $0.67(0.32-1.41)$ & $2.33(0.78,6.9)$ \\
\hline Self-employed & 12 & & $0.39(0.20-0.78)^{* *}$ & $0.50(0.23,1.10)$ \\
\hline \multicolumn{5}{|l|}{ Hypertension status } \\
\hline Yes & 44 & 49 & $1.69(1.09-2.64)^{*}$ & $1.43(0.21,9.73$ \\
\hline Do not know & 11 & 46 & $0.45(0.23-0.89)^{* *}$ & $0.82(0.12,5.47)$ \\
\hline No & 191 & 360 & 1.00 & 1.00 \\
\hline \multicolumn{5}{|l|}{ Diabetes mellitus status } \\
\hline Yes & 27 & 31 & 1.54(0.90-2.66) & $2.34(0.36,15.21)$ \\
\hline Do not know (unscreened) & 9 & 52 & $0.31(0.15-0.64)^{* *}$ & $1.92(0.31,11.96)$ \\
\hline No & 210 & 272 & 1.00 & 1.00 \\
\hline \multicolumn{5}{|l|}{ Eye examination } \\
\hline Yes & 126 & 135 & $2.49(1.81-3.3)^{* * *}$ & $2.78(1.86,4.15)^{* * *}$ \\
\hline No & 120 & 320 & 1.00 & 1.00 \\
\hline
\end{tabular}

$C O R$ adjusted odds ratio, $A O R$ adjusted odds ratio, $\mathrm{Cl}$ confidence interval

${ }^{*} p$-value $<0.05,{ }^{* *} p$-value $<0.01,{ }^{* * *} p$-value $<0.001,1=$ reference, others: retired, driver, religious leader, farmer, no job daily laborer

also be one possible explanation. In the Agaro study the participants were relatively aged (average 54.5) than participants in this study (average 48 years). Previous studies demonstrated older people are less aware of glaucoma [40, 44, 46, 61, 63].
This finding is also higher than reports from urban (4.8\%) [20] and rural settings $13.5 \%$ [12],0.32\% [53], $8.3 \% 5$ [54] of India which might be attributable to differences in study setting as well as socio-demographic differentials. 
Table 5 Bivariate and multivariate logistic regression of factor affecting good knowledge about glaucoma, Gondar town, $2016(n=246)$

\begin{tabular}{|c|c|c|c|c|}
\hline \multirow[t]{2}{*}{ Variable } & \multicolumn{2}{|c|}{ Knowledge } & \multirow[t]{2}{*}{ COR $(95 \% \mathrm{Cl})$} & \multirow[t]{2}{*}{ AOR $(95 \% \mathrm{Cl})$} \\
\hline & Good & Poor & & \\
\hline \multicolumn{5}{|l|}{ Age category (years) } \\
\hline $35-44$ & 50 & 62 & 1.00 & \multirow[t]{5}{*}{-} \\
\hline $45-54$ & 38 & 31 & $1.52(0.83,2.78)$ & \\
\hline $55-64$ & 24 & 18 & $1.65(0.81,3.38)$ & \\
\hline $65-74$ & 6 & 4 & $1.86(0.50,7.0)$ & \\
\hline$\geq 75$ & 4 & 9 & $0.55(0.16,1.90)$ & \\
\hline \multicolumn{5}{|l|}{ Sex } \\
\hline Male & 73 & 64 & .00 & 1.00 \\
\hline Female & 49 & 60 & $0.72(0.43,1.19)^{c}$ & $0.76(0.44,1.30)$ \\
\hline \multicolumn{5}{|l|}{ Educational level } \\
\hline No formal education & 7 & 24 & 1.00 & 1.00 \\
\hline Primary education & 28 & 34 & $2.82(1.06,7.52)^{*}$ & $2.83(1.04,7.71)^{*}$ \\
\hline Secondary education & 41 & 35 & $4.02(1.55,10.44)^{* *}$ & $3.53(1.33,9.41)^{*}$ \\
\hline College and above & 46 & 31 & $5.09(2.00,13.25)^{* *}$ & $4.86(1.82,12.99)^{* *}$ \\
\hline \multicolumn{5}{|l|}{ Marital status } \\
\hline Single & 12 & 6 & 1.00 & \multirow[t]{4}{*}{-} \\
\hline Married & 89 & 97 & $0.46(1.65,2.17)^{* *}$ & \\
\hline Divorced & 12 & 10 & $0.60(0.17,2.17)$ & \\
\hline Widowed & 9 & 11 & $0.41(0.11,1.53)$ & \\
\hline \multicolumn{5}{|l|}{ Diabetes mellitus status } \\
\hline Yes & 15 & 106 & $0.79(0.35,1.76)$ & \multirow[t]{3}{*}{-} \\
\hline Do not know & 104 & 104 & $0.40(0.08,1.94)$ & \\
\hline No & 3 & 6 & 1.00 & \\
\hline \multicolumn{5}{|l|}{ Hypertension status } \\
\hline Yes & 22 & 22 & $1.05(0.55,2.03)$ & \\
\hline Do not know(not screened) & 98 & 93 & $0.22(0.43,1.15)$ & \\
\hline No & 2 & 9 & 1.00 & \\
\hline \multicolumn{5}{|l|}{ Eye examination } \\
\hline Yes & 77 & 49 & $2.62(1.57,4.38)^{* * *}$ & $2.61(1.53,4.45)^{* * *}$ \\
\hline No & 45 & 75 & 1.00 & 1.00 \\
\hline
\end{tabular}

COR crude odds ratio, $A O R$ adjusted odds ratio, $\mathrm{Cl}$ confidence interval

${ }^{c}=p<0.20,{ }^{*} p<0.05,{ }^{* *} p<0.01,{ }^{* * *} p<0.001,1=$ reference

However, the finding of the present study is lower than the finding from urban population of Puducherry, India (45\%) [44], Pakistan (48.7\%) [50], Iran (46.6\%) [52] and North-central Nigeria (47\%) which might be due to the difference in the way awareness was measured. The present study has used a little bit 'stricter' definitions to measure awareness and knowledge of glaucoma. In those previous studies, a study participant were considered aware of glaucoma if the respondent was able to provide a 'Yes' response only for the question "Have you heard of glaucoma". However, in the present study a participant was considered aware of glaucoma if a 'Yes' response was obtained to the question 'Have you heard of glaucoma?' and additional description such as 'glaucoma is high eye pressure, 'glaucoma is high eye pressure causing blindness,' 'glaucoma is high eye pressure causing damage to the eye nerve' or similar explanation was obtained. Socio-economic variations could explain these differences. Other studies from Ghana (74\%) [58], Nigeria (74.3\%) [56] and Southwest Nigeria 68.6\% [57] also showed higher findings than this study which could partially be explained by variation in participants characteristics. In the former study, participants were glaucoma patients who were aware due to exposure to glaucoma related information [67].

On the other hand, the present study finding is in line with a study from central Ethiopia, Addis Ababa, Menelik 
II hospital in 2010 (28.4\%) [61]. This might be due to the similarity in socio-demographic characterstics of study pasrticipants, study design, setting. The former and the present study were urban based cross sectional studies and the study participants had similar socio-demographic characteristics with similar male to female participants ratio (1:1.1vs 1:1.6), age ( 40.5 vs. 48 years) and educational level.

From the three studies in Ethiopia, despite the different study population and settings, it appears that there is a paradigm shift of awarness about glaucoma. The due attention given to galucoma in the recent few years [24] may explain this. This could also be the effect of the expansion in eye care service through the increasing number of eye care professionals (optometrists and ophthalmologists) in Ethiopia [24].

The current study has also revealed better knowledge (49.6\%) about glaucoma compared to similar studies in urban community of India $0.5 \%$ [12] and 34.04\% [44], Ethiopia (12.1\%) [61],South India (3.1\%) [20] and Ghana (27\%) [58]. This might be due to the difference methods used to measure knowledge across these studies. In the former studies the proportion of knowledge estimated from total study participants (both aware and not aware as a denominator) whereas in this study knowledge was estimated among those who were aware of glaucoma.

While the current finding is in line with an institution based study in Benin city, Nigeria (31\%) [56], it was lower than a finding from Southwest Nigeria (88.3\%) [57]. This might reflect the method used to estimate knowledge was different across these studies and the characteristics of the study participants was quite different from the present study. In the Benin City, Nigerian study measure knowledge was consistent in content (included risk factors, symptoms, treatment, and prevention of glaucoma) with the current study. Additionally, majority $(77.8 \%)$ of the study participants had at least primary education, which is comparable with this study (67.8\%).

In this study, people with at least primary education were better aware of glaucoma. Similar finding was also reported from Ethiopia [61] where better education was positively related with awareness of glaucoma. This could be due to the fact that the chance of exposure to different health related information education communication means increases as educational status increase [13, 41, 43, 44, 49, 51, 61-63].

Older individuals (age group $65-74$ ) were 69\% less likely to be aware of glaucoma compared with those individuals in the age group $35-44$. Similar finding [40] was also reported that where older people were less aware of glaucoma. However, in this study lower awareness was observed among adults between 65 and 74 years of age. The explanation for this may require a detailed study in this segment (age 65-74) of population. However, the current study found a smaller proportion of awareness of glaucoma (1.4\%) among people age 65 - 74 years. Additionally, the proportion of risk factors for glaucoma including hypertension $(1.12 \%)$ and diabetes mellitus $(2.13 \%)$ were common and history of eye examination was reported in only $5.7 \%$ out of the total 701 -study population. These findings may reflect that this segment of population is preoccupied with other general health issues.

It was also indicated that adults who had eye examination at least once in their life were more likely to be aware of glaucoma. Similar result was reported from Osun State, Nigeria [64].

According to this study, primary and above educational level was positively associated with better knowledge about glaucoma. This might be due to the higher number of literates, which may seek health related information that probably leads to awareness. In this study, $31.5 \%$ of the study participants were aware of glaucoma and above $62 \%$ were literates. In Indian study, knowledge increases exponentially among people with above college education [40]. Similar finding was also reported from other studies [13, 41, 44, 51, 63].

Eye examination at least once in life was related with good knowledge about glaucoma in this study. This is in line with a study from Osun State, Nigeria [64]. This might be due to the health education given for patients coming for eye examination help them to acquire some basic knowledge about the disease.

In previous studies, sex $[44,48]$ type of occupation [51, 64] history diabetes, hypertension [20], positive family history of glaucoma $[46,63]$ were significant determinants of awareness and knowledge of glaucoma. However, the data in the current study did not support this. This could be due to the small number of cases in this study.

\section{Strength of the study}

Being community based, this study revealed the actual picture of public awareness and knowledge of glaucoma Using face-to-face interview allowed for clarification of misunderstood questions and reduced the frequency of missing items in the questionnaire.

\section{Limitations of the study}

The study had some limitations that should be taken into account. It studied only residents who lived in households and homeless and people living in institutions (religious peoples, military, teachers and physicians) were not included which could either inflate or underestimate the reported finding in this study. Interviewer bias could not be eliminated as an individual's expression, and style of explanation may affect the response of the participant. Data were also based on self-reporting which is subject to recall bias and income was not included in the analysis. The 
questionnaire was designed considering only primary open angle glaucoma. As a result, it was not possible to measure awareness and knowledge of people on other types of glaucomas. This study did not assess the attitude of participants towards glaucoma, which might have an impact on acquiring knowledge that might affect the knowledge assessment.

\section{Conclusion}

The study has indicated the present level of awareness and knowledge among urban resident adults is high. It has also identified having at least primary education, eye examination at least once in life to be associated with better awareness and knowledge. It also identified mass media to be the main source of information about glaucoma.

\section{Additional files}

Additional file 1: Sample size determination using the single population formula for awareness and knowledge (DOCX $13 \mathrm{~kb}$ )

Additional file 2: Sampling technique (DOCX $14 \mathrm{~kb}$ )

Additional file 3: English version of questionnaire (DOCX $26 \mathrm{~kb}$ )

Additional file 4: Data collection procedures (DOCX $13 \mathrm{~kb}$ )

\section{Abbreviations}

CSA: Central Statistical Agency; OSE: Ophthalmological Society of Ethiopia; POAG: Primary open angle glaucoma; SPSS: Statistical Package for Social Sciences

\section{Acknowledgements}

The authors would like to thank University of Gondar for its financial support to carry out the study. Our gratitude also goes to the study participants and data collectors.

\section{Funding}

The study was financially supported by University of Gondar.

\section{Availability of data and materials}

Dataset on which the conclusion was made is available in software and only available on request from Mr. Destaye Shiferaw (contact address: destayest@gmail.com).

\section{Authors' contributions}

DS conceived the idea, developed the proposal, analyzed the data and write up the paper. $A D$ and $K L$ critically reviewed incorporated comments into paper. All authors read and approved the final manuscript.

\section{Ethics approval and consent to participate}

The research was approved by the ethical review committee of University of Gondar. Support letter from respective administrative areas (kebeles) was obtained. Participants were informed the purpose of the study and participation was voluntary. Confidentiality was kept by coding personal identity and locking data with password. Data collectors gave education to those participants who were not aware and those who had misunderstood information about glaucoma.

\section{Consent for publication}

Not Applicable

\section{Competing interests}

The authors declare that they have no any competing interests.

\section{Publisher's Note}

Springer Nature remains neutral with regard to jurisdictional claims in published maps and institutional affiliations.

Received: 25 July 2016 Accepted: 8 August 2017

Published online: 24 August 2017

\section{References}

1. Kanski JJ. Glaucoma. In: Kanski JJ, editor. Clinical ophthalmology a systemic approach. 7th ed. Edinburgh, London, New York, Oxford, Philadelphia, St Louis, Sydney, Toronto: Butterworth \& Heinmann Elsevier Saunders publisher; 2011. p. 3510.

2. Malu KN, Ojabo CO. Ocular health survey among the staff of Benue state university teaching hospital, Nigeria. Sub-Saharan J Med. 2014;1:65.

3. Mafwiri M, Bowman R, Wood M, Kabiru J. Primary open-angle glaucoma presentation at a tertiary unit in Africa: intraocular pressure levels and visual status. Ophthalmic Epidemiol. 2005;12:299-302.

4. Johannes $\mathrm{G}$. The pathogenesis of glaucoma in the interplay with the immune system. Invest Ophthalmol Vis Sci. 2013;54(3):2393-409.

5. Williams SE. The genetics of POAG in black south Africans: a candidate Gene Association study. Sci Rep. 2015;5:8378.

6. Allingham $R$, Liu Y, Rhee $D$. The genetics of primary open-angle glaucoma: a review. Exp Eye Res. 2009;88(4):837-44.

7. Takamoto M, Araie M. Genetics of primary open angle glaucoma. Jpn J Ophthalmol. 2014;58(1):1-15.

8. Hollands H, Johnson D, Hollands S, Simel DL, Jinapriya D, Sharma S. Do findings on routine examination identify patients at risk for primary openangle glaucoma? JAMA. 2013;309:2035-42.

9. World Health Organization. Global data on visual impairments. 2010. http:// www.who.int/blindness/Globaldatafinalforweb.pdf. Accessed 29 Mar 2016.

10. Suraj S, Lene P, Binjwala S, Andrej M, Alexandra K. Understanding and living with glaucoma and non-communicable diseases like hypertension and diabetes in the Jhaukhel-Duwakot health demographic surveillance site: a qualitative study from Nepal. Glob Health Action. 2014;7:25358.

11. Pascolini D, Mariotti P. Global estimates of visual impairment: $2010 . \mathrm{Br} J$ Ophthalmol. 2012;96:614-8.

12. Sathyamangalam R, Paul G, George R, Bhaskaran M, Hemamalini A, Madan RV. Determinants of glaucoma awareness and knowledge in urban Chennai. Ind J Ophthalmol. 2009:57:355-60.

13. Chaitra P, Laxman D, Jayshree $P$, Madhuri $P$, Puneet SS. Evaluation of the awareness on glaucoma in a rural eye camp in North Karnataka, India. J Clin Diagn Res. 2012;6(7):1226-8.

14. Quigley HA, Broman AT. The number of people with glaucoma worldwide in 2010 and 2020. Br J Ophthalmol. 2006;90:262-7.

15. Tham Y. Global prevalence of glaucoma and projections of glaucoma burden through 2040: a systematic review and meta-analysis. Ophthalmology. 2014;121(11):2081-90.

16. Venediktos VK, Michelle P, Foster PJ, Derek GC, Christopher GO, Alicja RR. Global variations and time trends in the prevalence of primary open angle glaucoma (POAG): a systematic review and meta-analysis. Br J Ophthalmol. 2015:1-8.

17. Kyari F, Abdull M, Bastawrous A, Gilbert CE, Faal H. Epidemiology of glaucoma in sub-Saharan Africa: prevalence, incidence and risk factors. Middle East Afr J Ophthalmol. 2013;20:111-25.

18. Yih-Chung T, Xiang L, Tien Y, Harry A, Tin A, Ching-Yu C. Global prevalence of glaucoma and projections of glaucoma burden through 2040: systematic review and meta-analysis. Ophthalmology. 2014;121:2081-209.

19. Yemane B, Alemayehu W, Abebe B, Liknaw A, Wondu A, Amir B, et al. Prevalence and causes of blindness and low vision in Ethiopia. EthiopJHealth Dev. 2007:21(3):204-10.

20. Mridula P, Shankargouda P, Chandra R, Pravin K. Glaucoma awareness and knowledge in a tertiary care hospital in a tier-2 city in South India. J Sci Soc. 2013:40(1):3.

21. Van Gestel A, Webers CA, Beckers HJ. The relationship between visual field loss in glaucoma and health-related quality-of-life. Eye (London, England). 2010;24:1759-69.

22. Do S, Hans L. Report of the rapid assessment for avoidable blindness in Cambodia. National Program for eye health. 2007.

23. Cristina F, Kafi S, Otavio C, Dave $P$, Jonathan C, Marcelo H. Burden of disease in patients with glaucoma in Brazil: results from 2011-2012 national health 
and wellness survey. Poster presented at the ISPOR 18th annual European congress 7-11 November 2015 Milan, Italy.

24. Abeba TG. Raising public awareness of glaucoma in Ethiopia. Community Eye Health J. 2012.

25. Michaeline Al, Mustapha BH, Patience OA, Olalekan WA, Esther OA, Alebiosu CC. Awareness of and attitude towards glaucoma among an adult rural population of Osun state, Southwest Nigeria. Middle East Afr J Ophthalmol. 2014;21(2):165-9.

26. Keziah NM, Nguavese HO, Doosuur M, Dalton NG. The role of the mass media in creating awareness about eye diseases. J Med Res Pract. 2014;3(2):76-80

27. Maier PC, Funk J, Schwarzer G, Antes G, Falck-Ytter YT. Treatment of ocular hypertension and open angle glaucoma: meta-analysis of randomized controlled trials. BMJ. 2005;331:134-9.

28. Tuulonen A. Cost-effectiveness of screening for open angle glaucoma in developed countries. Indian J Ophthalmol. 2011;59(Suppl):S24-30.

29. Mansouri K, lliev ME, Rohrer K, Shaarawy T. Compliance and knowledge about glaucoma in patients at tertiary glaucoma units. Int Ophthalmol. 2011:31:369-76.

30. Chen X, Chen Y, Sun X. Notable role of glaucoma club on patients' knowledge ofglaucoma. Clin Exp Ophthalmol. 2009;37:590-4.

31. Kenneth $\mathrm{BO}$, Seth $\mathrm{BT}$, Ankrah LM, Emmanuel AO. Prevalence of glaucoma in an eye clinic in Ghana. Russ Open Med J. 2013:2(0310).

32. Burr JM, Mowatt G, Hernandez R, Siddiqui MA, Cook J, Lourenco T. The clinical effectiveness and cost-effectiveness of screening for open angle glaucoma: a systematic review and economic evaluation. Health Technol Assess. 2007;11:iii-V. ix-X, 1-190

33. Ng WS, Agarwal PK, Sidiki S, McKay L, Townend J, Azuara-Blanco A. The effect of socio-economic deprivation on severity of glaucoma at presentation. Br J Ophthalmol. 2010;94:85-7.

34. Bowman RJ, Hay A. Combined cataract and trabeculectomy surgery for advanced glaucoma in East Africa; visual and intra-ocular pressure outcomes. Eye (Lond). 2010;24:573-7.

35. Achigbu EO, Chuka-Okosa CM, Achigbu KI. The knowledge, perception, and attitude of patients living with glaucoma and attending the eye clinic of a secondary health care facility in south-east, Nigeria. Niger J Ophthalmol. 2015;23:1-6.

36. Prabhu M, Patil SH, Kangokar PR. Glaucoma awareness and knowledge in a tertiary care hospital in a tier-2 city in South India. J Sci Soc. 2013:40:3-8.

37. Wittenborn JS, Rein DB. Cost-effectiveness of glaucoma interventions in Barbados and Ghana. Optom Vis Sci. 2011;88(1):155-63.

38. Cross V, Shah P, Bativala R, Spurgeopn P. Glaucoma awareness and primary eye- careservice: some perceptions among African Caribbean's in Birmingham UK. Eye (Lond). 2007;21 (7):912-20.

39. Foster A, Resnikoff $S$. The impact of vision 2020 on global blindness. Eye (Lond). 2005;19:1133-5.

40. Jin YP, Miller G, Lin K, Trope GE. Glaucoma knowledge in a black community in Toronto. Int J Ophthalmol Eye Res. 2014;2(5):59-64.

41. Christina C, Alves G, Eugênio I, Anbar J, Md M. Knowledge about glaucoma and epidemiological profile of subjects seen in a campaign conducted at the university hospital Lauro Wanderley. Rev Bras Oftalmol. 2014;73(1):33-6.

42. Parveen R, Mukesh K. Awareness, knowledge and practice: a survey of glaucoma in north Indian rural residents. Indian J Ophthalmol. 2014;62:482-6.

43. Jothi R, Siddhartha P, Ismail R, Senthamarai C. Impact of education on knowledge attitude and practice (KAP) of glaucoma patients towards their disease management- a study. J Pharm Res Clin Pract. 2013;3(1):8-12.

44. Muthu KV, Baba D, Rathna K, Natarajan S, Divya S. Prevalence of awareness and knowledge of glaucoma in urban Puducherry. Sch J App Med Sci. 2015; 3(7B):2561-7.

45. Albina R, Khaled K, Orna G, Cohen CO. Primary care physicians' role perception and self reported performance in glaucoma care: a survey study. BMC Res Notes. 2015;8:776.

46. Anuli MC, Olukorede OA. The awareness, perceptions and experiences of primary open angle glaucoma patients in Lagos Nigeria. Sci Rep. 2015;4:7585.

47. Mbadugha CA, Onakoya AO. The awareness, perceptions and experiences of primary open angle glaucoma patients in Lagos Nigeria. Sci Rep. 2014;4:7585.

48. Krishnaiah S, Kovai V, Srinivas M, Shamanna BR, Rao GN, Thomas R. Awareness of glaucoma in the rural population of southern India. Indian J Ophthalmol. 2005:53:205-8.

49. Costa VP, Spaeth GL, Maura S, Cordelia U, Paulo JV, Kara-José N. Patient education in glaucoma: what do patients know about glaucoma? Arq Bras Oftalmol. 2006;69(6):923-7.
50. Nasira I, Muhammad M, Asif M. Awareness of glaucoma in different groups of urban population. Pak J Ophthalmol. 2014;30(3):142.

51. Farooq S, Jaffar S, Kausar A. Determinants of glaucoma awareness in urban punjab. Pak Armed Forces Med J. 2015;65(5):591-4

52. Marzieh K, Hossein Z, Elnaz P, Hamid-Reza M, Sara H, Masumeh K, et al. Knowledge and awareness of age related eye diseases: a population-based survey. J Ophthalmic Vis Res. 2014;9(2):223-31.

53. Sannapaneni K, Vilas K, Marmamula S, Bindiganavale S, Gullapalli R, Ravi T. Awareness of glaucoma in the rural population of southern India. Indian J Ophthalmol. 2005;53:205-8.

54. Rewri P, Kakkar M. Awareness, knowledge, and practice: a survey of glaucoma in north Indian rural residents. Indian J Ophthalmol. 2014;62:482-6.

55. Mohammed M, Abdull CC, Gilbert JE. Primary open angle glaucoma in northern Nigeria: stage at presentation and acceptance of treatment. BMC Ophthalmol. 2015;15:111.

56. Osaguona VB, Edema OT. Awareness and knowledge of glaucoma among hospital workers at the University of Benin Teaching Hospital, Benin City. Sahel Med J. 2014;17(4):132.

57. Condition $\mathrm{OO}$, Komolafe CO, Omolase CO, Bekibele OA, Ogunleye OA, Komolafe FO, et al. Awareness and knowledge of glaucoma among Workers in a Nigerian Tertiary Health Care Institution. Middle East Afr J Ophthalmol. 2013;20(2):163.

58. Nkum G, Lartey S, Frimpong C, Micah F, Nkum B. Awareness and knowledge of glaucoma among adult patients at the eye clinic of a teaching hospital. Ghana Med J. 2015;49:195-9.

59. Yewubnesh H, Abeba T, Assegid A. Know-how of primary eye care among health extension workers (HEWs) in southern Ethiopia. Ethiop J Health Dev. 2009;23(2):127-32

60. Addis T, Berhan S, Amare D. Glaucoma a awareness among people attending ophthalmic outreach services in southwestern Ethiopia. BMC Ophthalmol. 2010;10(17):17.

61. Hiwot D, Abeba TG. Glaucoma awareness among ophthalmic patients at Menelik II hospital, Addis Ababa, Ethiopia. Ethiop J Health Dev. 2013;27(3): 230-134.

62. Divya V, Suvarna G. Glaucoma awareness among patients at outpatient Department of Ophthalmology in Smt. Kashibai Navale medical college and general hospital, Narhe, Pune. Int J Sci Res (IJSR). 2012:2319-7064.

63. Sandhya R, Abhilasha S, Niharika S. A study of awareness of glaucoma among ophthalmology out patients in a 2-Tier City, Tumkur. Indian J Clin Exp Ophthalmol. 2015;1(3):156-8.

64. Adegbehin $\mathrm{BO}$, Isiriyu LA. Knowledge, attitudes, and self care practices associated with glaucoma among hospital workers in lle-lfe, Osun state, Nigeria. Tanzan J Health Res. 2008;10(4):240-5.

65. Ferderal Democratic Republic of Ethiopia. Ethiopian central statistical population and housing Censu 2007.

66. Al-Mandhari A, Al-Adawi S, Al-Zakwani I, Al-Shafaee M, Eloul L. Impact of geographic proximity on health care seeking behaviour in Northen Oman. Sultan Qaboos Univ Med J. 2008:8(3):310-8.

67. Shahed $\mathrm{S}$. The impact of health information provision on breast cancer related knowledge and protective behaviors: an experiment in health education. Lahore J Econ. 2013;18(1):117-33.

\section{Submit your next manuscript to BioMed Central and we will help you at every step:}

- We accept pre-submission inquiries

- Our selector tool helps you to find the most relevant journal

- We provide round the clock customer support

- Convenient online submission

- Thorough peer review

- Inclusion in PubMed and all major indexing services

- Maximum visibility for your research

Submit your manuscript at www.biomedcentral.com/submit
) Biomed Central 